\title{
A GREENER APPROACH FOR THE DEGRADATION OF DYE METHYLENE BLUE BY ORGANIC ADDITIVE CATALYSED PHOTO - FENTON PROCESS
}

\author{
JAIN ABHILASHA*, AGGARWAL ASHMA and KOTWAL MARAZBAN \\ Department of Chemistry, St. Xavier's College, 5, Mahapalika Marg, MUMBAI- 400001
}

\begin{abstract}
Fenton and photo-Fenton processes are proven to be most promising techniques for the wastewater treatment methods. It provides an attractive method for degradation of dyes and breaks them into simple mineral form. These are cost effective and ecologically viable techniques with additional advantages of relatively simple approach, use of less hazards chemicals for the degradation and cyclic nature. Thus, it serves as a green chemical and eco-friendly pathway in reducing pollution caused by complex dye molecule and other organic compounds. Present work has been designed to investigate photochemical degradation of dye Methylene blue by photo-Fenton reaction in presence of resorcinol as an additive. Kinetic study of the reaction has been made by using spectrophotometric technique

Effect of variation of various operating parameters such as $\mathrm{pH}$, concentration of $\mathrm{Fe}^{3+}$ ion, dye and additive; amount of $\mathrm{H}_{2} \mathrm{O}_{2}$ and light intensity has also been observed. A tentative mechanism for the photo-Fenton reaction in presence of organic additive is also given.
\end{abstract}

Key Words: Advanced Oxidation Processes (AOP’s), Photo-Fenton, Decolorization, Methylene blue, Recorcinol.

\section{INTRODUCTION}

The treatment of industrial effluent which may contain a variety of suspended solids, oils, metals, ceramics and organic compounds like dyes, paints and adhesives is absolutely imperative as wastewater pose a great threat to aquatic life. An important and active area of_environmental chemistry is the search for cheap, simple and effective methods to destroy recalcitrant pollutants $^{[1-3]}$. In this respect degradation of dyes has been given more attention by researchers as there are nearly one million tonnes of dye stuff produce globally per annum, which are based on more than 10,000 different structures ${ }^{[46]}$. The presence of dyes, hinders the photosynthetic activity of aquatic plants when discharged into water bodies. Moreover, many dyes are cleverly designed to be highly stable towards light, aerobic biodegradation, and common oxidants such as hydrogen peroxide or even hypochlorite, making chemical removal extremely difficult. Physical methods, such as adsorption onto activated carbon, partially removes some dyes, but leaves the problem of safe disposal of the concentrated dye ${ }^{[7]}$.

The successful removal of dye from the effluents prior to discharge, using existing treatments, are constantly being modified by researchers all over the world. In the last one and a half decades, methods based on advanced oxidation processes (AOPs) have assumed great importance. In such processes, very reactive radicals are generated which efficiently oxidize the organic pollutants either directly or via reactions with dissolved oxygen. Advanced oxidation processes (AOPs) in general include oxidation techniques using either of the following: $\mathrm{UV} / \mathrm{O}_{3}, \mathrm{O}_{3} / \mathrm{H}_{2} \mathrm{O}_{2}, \mathrm{UV} / \mathrm{H}_{2} \mathrm{O}_{2}$ or the Fenton $\left(\mathrm{H}_{2} \mathrm{O}_{2} / \mathrm{Fe}^{2+}\right.$ or $\left.\mathrm{Fe}^{3+}\right)$ or photo Fenton reagent ( $\left(\mathrm{UV}\right.$-vis/ $/ \mathrm{H}_{2} \mathrm{O}_{2} / \mathrm{Fe}^{2+}$ or $\mathrm{Fe}^{3+}$ ). In these processes the organic dye molecules are oxidised to carbon dioxide, water and/or biodegradable compounds ${ }^{[8]}$. AOPs involving Fenton and Photo-Fenton is found to be highly effective and efficient in the quick removal of dyes from effluents. The degradation of different commercial reactive dyes by using solar light assisted Fenton and photo-Fenton reaction has been investigated by numerous researchers ${ }^{[9]}$ and the mechanism as well as kinetics of the reaction has been extensively studied in the past ${ }^{[10-17]}$. Fenton's reagent which is a mixture of $\mathrm{H}_{2} \mathrm{O}_{2}$ and ferrous iron, generates hydroxyl radicals with the ferrous $\left(\mathrm{Fe}^{2+}\right)$ ions initiating and catalysing the decomposition of $\mathrm{H}_{2} \mathrm{O}_{2}$, resulting in the generation of hydroxyl radicals. Though the generation of these radicals involves a complex reaction sequence in an aqueous solution ${ }^{[18]}$ the method can be used for wide scale treatment of effluent waters as the process does not generate any sludge ${ }^{[19-24]}$. The overall efficiency of photo-Fenton-type oxidation depends on specific parameters and their relationships in terms of formation and utilization of hydroxyl radicals. Concentration of the reactants (catalyst $\mathrm{Fe}^{2+} / \mathrm{Fe}^{3+}$ and oxidant $\mathrm{H}_{2} \mathrm{O}_{2}$ ), irradiation intensity, reaction $\mathrm{pH}$, initial pollutant concentration (dye) etc., all contribute to the treatment performance, and thus need to be carefully optimized.

Addition of other compounds has been found to greatly influence the Fenton degradation of target organic compounds in the dark ${ }^{[25-28]}$. Aromatic derivatives, such as hydroquinone and hydroquinone-like compounds, were found to have a catalytic action to enhance the Fenton degradation of organic compounds in the dark ${ }^{[29-31]}$. Similarly, the degradation of dye under UV and visible light using Fenton reagent is found to be better with the addition of several organic and inorganic additives which themselves decompose during the degradation of dyes to form environmentally benign products. ${ }^{[32-46]}$. However, a large amount of work is still required to be done to understand the catalytic behaviour of aromatic derivatives in the photo-Fenton degradation of dyes.

Present work shows the utility of resorcinol, an aromatic compound, to catalyse the visible light assisted photo-Fenton degradation of dye methylene blue.

\section{MATERIALS AND METHODS}

Stock solutions of $1 \times 10^{-3} \mathrm{M}$ concentration of dye (Methylene blue, E.Merck, A.R), Resorcinol (E.Merck, A.R) and $\mathrm{FeCl}_{3}$ (LOBA, A.R) were prepared in doubly distilled water. Commercially available $30 \% \mathrm{w} / \mathrm{v}$ hydrogen peroxide (E.Merck A.R) was used. All the chemicals were used directly as received commercially without any further purification. For the typical run, 30 $\mathrm{cm}^{3}$ reaction mixture was prepared by adding all reagents one after the other A concentration of $2.33 \times 10^{-5} \mathrm{M}$ for dye, $9.33 \times 10^{-5} \mathrm{M}$ for ferric chloride and $9.33 \times 10^{-5} \mathrm{M}$ for resorcinol was achieved in the reaction mixture and 0.16 $\mathrm{cm}^{3}$ of $\mathrm{H}_{2} \mathrm{O}_{2}$ was added to the solution. The $\mathrm{pH}$ of the above solution was maintained at 3.00 and kept under the light of 6000 lux intensity. These specific concentrations were selected on the basis of optimization of each parameter. The optimal value for one parameter, once established, was kept constant and other parameters were changed one after the other to get their optimum values.

For the irradiation of solution a $200 \mathrm{~W}$ tungsten lamp, which emits the radiations in the visible range of electromagnetic spectrum, was used. To measure the intensity of light Lux meter (LT Lutron electronics, model no: LX101A) was used. A petridish filled with water was used as water filter to cut off thermal radiations. A digital $\mathrm{pH}$ meter (Equiptronics, Model: EQ611) was used to measure the $\mathrm{pH}$ of the system. $0.1 \mathrm{M}$ sodium hydroxide and $0.1 \mathrm{M}$ sulphuric acid (both previously standardised) were used to adjust the $\mathrm{pH}$ of the solution to the required value. All the solutions were kept at room temperature. The kinetic study of photochemical reactions was done by measuring absorbance at regular intervals with the help of UV-Visible spectrophotometer (Chemiline, Model CL 340).

\section{RESULTS AND DISSCUSSION}

The absorbance or Optical Density (O. D.) of the dye in the reaction mixture was measured at $1_{\max }=660 \mathrm{~nm}$ after every 10 minutes using $3.0 \mathrm{~cm}^{3}$ of the aliquot. With increasing time of exposure, the absorbance or O.D. of the solution decreased which indicates a decrease in concentration dye. The results 
presented graphically in Fig (I A).

It has been observed that the reaction undergoes completion in two stages. The first stage is slow which probably involves the generation of the $\cdot \mathrm{OH}$ radicals can be considered as induction period. It shows a slight decrease in absorbance due to simple photochemical degradation of dye. In second stage, a significant decrease in absorbance has been observed. It shows a linear variation of $2+\log _{10}$ [O.D.] versus time and the reaction was found to follow pseudofirst order kinetics. The value of rate constant was calculated using expression:

\section{$\mathrm{k}=2.303 \times$ Slope}

This second stage is photo-Fenton degradation, where ${ }^{\circ} \mathrm{OH}$ radicals act as oxidizing agents for the degradation of dye. After that another third stage is also observed where the rate of reaction is again slow down due to having very less amount of dye towards the end of the degradation. Effect of variation of different parameters on the rate of reaction was studied by comparing the rates of the second stage of the photo-Fenton reaction.

It was also reported that the first stage (slow step or induction period) gets shorter time span as experimental conditions approached to the optimum values. A comparative study of Fig. (1 A) to (1 D) shows expedient degradation of dye in presence of additive in light. A very negligible degradation of dye was observed in the absence of organic additive (Resorcinol) in dark by Fenton process. The observations revealed that the organic additive accelerates reaction rate either by generating $\bullet \mathrm{OH}$ radicals rapidly or by providing more number of - $\mathrm{OH}$ radicals. Under optimal conditions of $\mathrm{pH}$, dye, $\mathrm{H}_{2} \mathrm{O}_{2}, \mathrm{FeCl}_{3}$, additive and light intensity the rate of degradation became very fast and induction period diminished almost to zero and third stage of reaction was observed.

FIG. I A : Typical Run - Photo-Fenton Degradation of Methylene Blue with Additive in Light.

\begin{tabular}{|c|c|}
\hline Methylene blue $=\left[2.33 \times 10^{-5} \mathrm{M}\right]$ & $\mathrm{pH}=3.00$ \\
\hline Amount of $\mathrm{H}_{2} \mathrm{O}_{2}=0.16 \mathrm{~cm}^{3}$ & $\mathrm{FeCl}_{3}=\left[9.33 \times 10^{-5} \mathrm{M}\right]$ \\
\hline Resorcinol $=\left[9.33 \times 10^{-5} \mathrm{M}\right]$ & Light Intensity $=6000$ Lux \\
\hline & With Additive in light \\
\hline
\end{tabular}

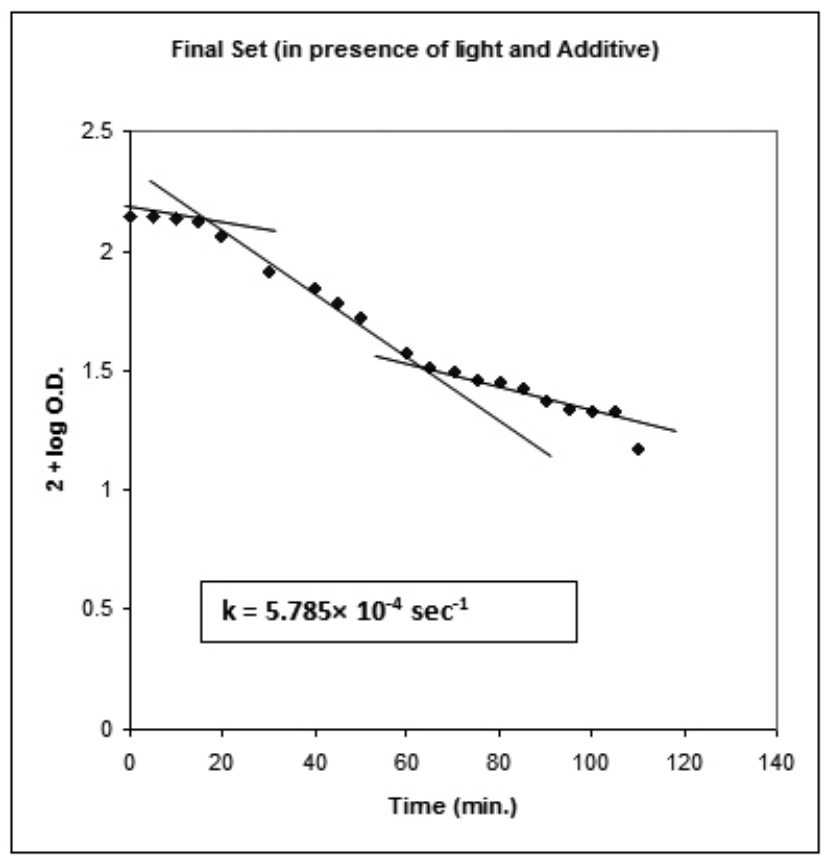

Fig. I B : Typical Run - Fenton Degradation of Methylene Blue with Additive in Dark.

\begin{tabular}{|c|c|}
\hline Methylene blue $=\left[2.33 \times 10^{-5} \mathrm{M}\right]$ & $\mathrm{pH}=3.00$ \\
\hline Amount of $\mathrm{H}_{2} \mathrm{O}_{2}=0.16 \mathrm{~cm}^{3}$ & $\mathrm{FeCl}_{3}=\left[9.33 \times 10^{-5} \mathrm{M}\right]$ \\
\hline Resorcinol $=\left[9.33 \times 10^{-5} \mathrm{M}\right]$ & With additive in Dark \\
\hline
\end{tabular}

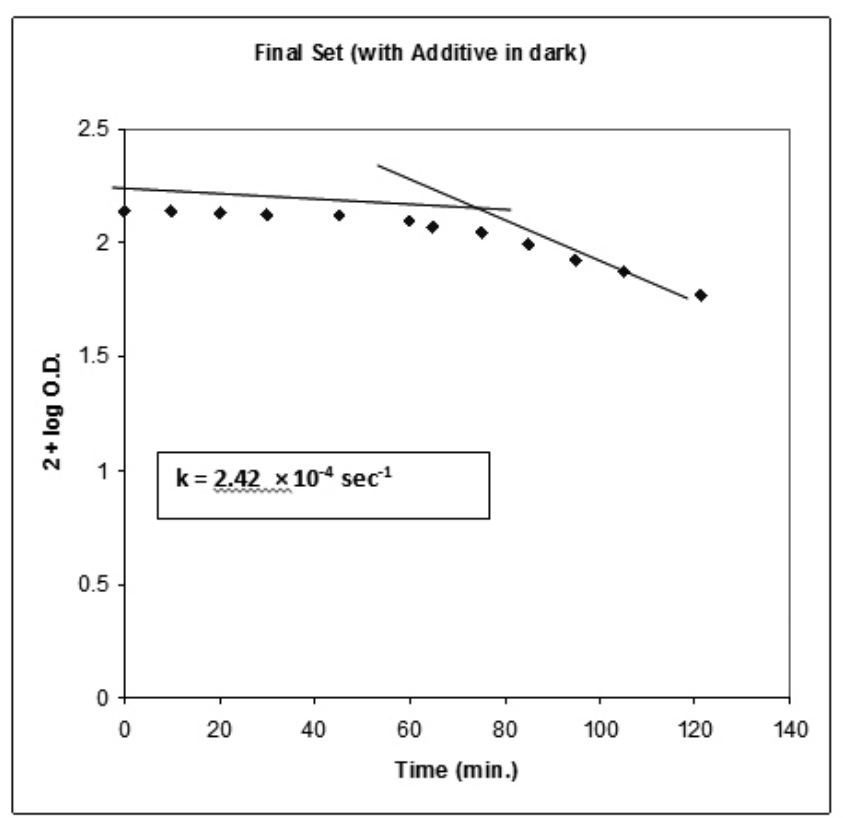

FIG. I C : Typical Run : Photo - Fenton Degradation of Methylene Blue without Additive in Light.

\begin{tabular}{|c|c|}
\hline Methylene blue $=\left[2.33 \times 10^{-5} \mathrm{M}\right]$ & $\mathrm{pH}=3.00$ \\
\hline Amount of $\mathrm{H}_{2} \mathrm{O}_{2}=0.16 \mathrm{~cm}^{3}$ & $\mathrm{FeCl}_{3}=[9.33 \times 10-5 \mathrm{M}]$ \\
\hline Resorcinol $=[9.33 \times 10-5 \mathrm{M}]$ & Without additive in light \\
\hline
\end{tabular}

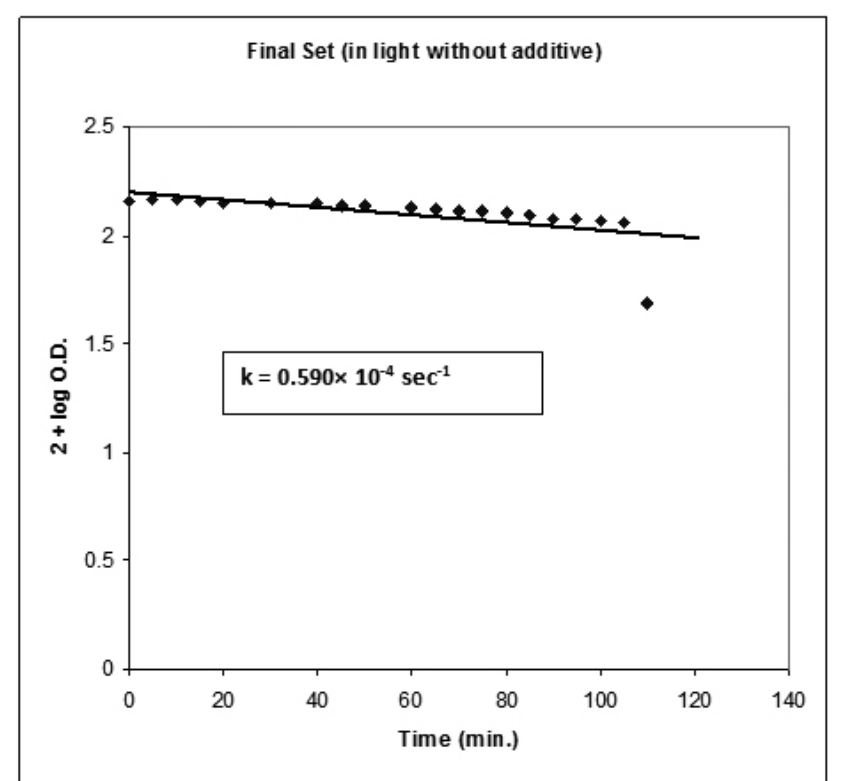


Fig. I D : Typical run - Photo-Fenton Degradation of Methylene Blue Without Additive in Dark.

\begin{tabular}{|c|c|}
\hline Methylene blue $=\left[2.33 \times 10^{-5} \mathrm{M}\right]$ & $\mathrm{pH}=3.00$ \\
\hline Amount of $\mathrm{H}_{2} \mathrm{O}_{2}=0.16 \mathrm{~cm}^{3}$ & $\mathrm{FeCl}_{3}=[9.33 \times 10-5 \mathrm{M}]$ \\
\hline Resorcinol $=[9.33 \times 10-5 \mathrm{M}]$ & Without additive in light \\
\hline
\end{tabular}

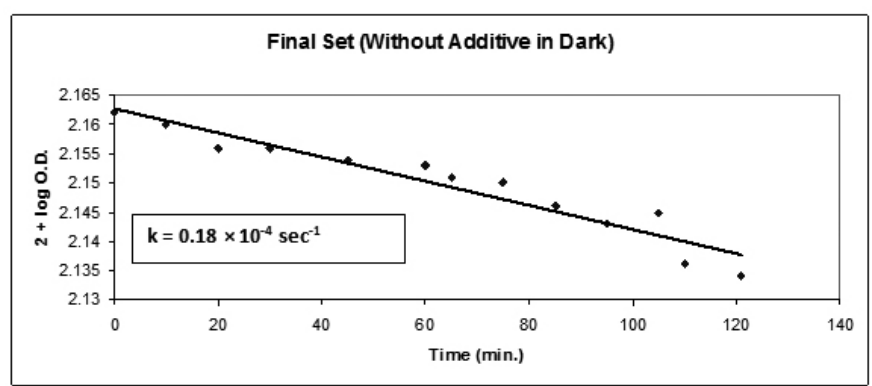

\subsection{Effect of $\mathrm{pH}$}

The effect of $\mathrm{pH}$ on additive catalyzed photochemical degradation was observed by varying $\mathrm{pH}$ from 2.25 to 4.00 whereas the values of other parameters were kept constant. The result of Fig. (2) indicates an increase in rates of degradation of dye Methylene blue with an increase in $\mathrm{pH}$ up to 3.00 after which the rate was found to decrease. Initially with increasing $\mathrm{pH}$ steps (4), (5) and (9) get accelerated. At higher $\mathrm{pH}$, ferric ions react with hydrogen peroxide to generate water and oxygen, instead of generating hydroxyl radicals, which is responsible species for the photochemical degradation of dye. Thus rate is found to be decreased.

FIG - 2 : Effect of pH on the Photo-Fenton Degradation of Dye.

\begin{tabular}{|c|c|}
\hline Methylene blue $=\left[2.33 \times 10^{-5} \mathrm{M}\right]$ & $\mathrm{FeCl}_{3}=\left[9.33 \times 10^{-5} \mathrm{M}\right]$ \\
\hline Amount of $\mathrm{H}_{2} \mathrm{O}_{2}=0.16 \mathrm{~cm}^{3}$ & Light Intensity $=6000$ lux \\
\hline Resorcinol $=\left[9.33 \times 10^{-5} \mathrm{M}\right]$ & \\
\hline
\end{tabular}

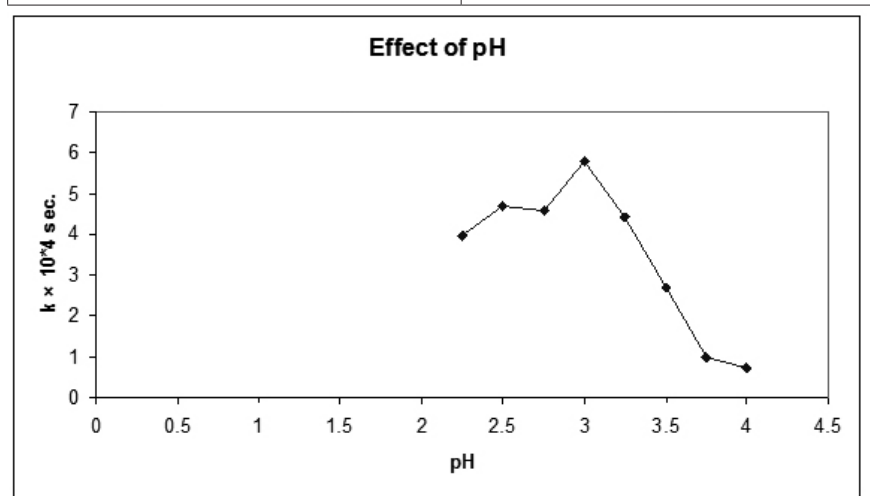

3.2 Effect of Ferric Ion Concentration

The effect of ferric chloride $\left[\mathrm{Fe}^{+3}\right.$ ions] concentration on the rate of photochemical degradation was investigated by changing the concentration from 0.00 to $10.67 \times 10^{-5} \mathrm{M}$, keeping all other parameters constant. The result shown in Fig. (3) indicates an increase in the rate of photo-Fenton degradation with increasing concentration of ferric ions up to $9.33 \times 10^{-5} \mathrm{M}$. $\mathrm{Up}$ to this particular $\mathrm{Fe}^{+3}$ ion concentration, an increase in the number of $\mathrm{Fe}^{3+}$ ions enhances the generation of $\bullet \mathrm{OH}$ radicals thus the rate of photochemical degradation is increased. At higher concentration of ferric ions, the rate of reaction was observed to be decreased.
FIG - 3: Effect of Concentration of $\mathrm{FeCl}_{3}$ on the Photo-Fenton Degradation of Dye.

\begin{tabular}{|c|c|}
\hline Methylene blue $=\left[2.33 \times 10^{-5} \mathrm{M}\right]$ & $\mathrm{pH}=3.00$ \\
\hline Amount of $\mathrm{H}_{2} \mathrm{O}_{2}=0.16 \mathrm{~cm}^{3}$ & Light Intensity $=6000$ lux \\
\hline Resorcinol $=\left[9.33 \times 10^{-5} \mathrm{M}\right]$ & \\
\hline
\end{tabular}

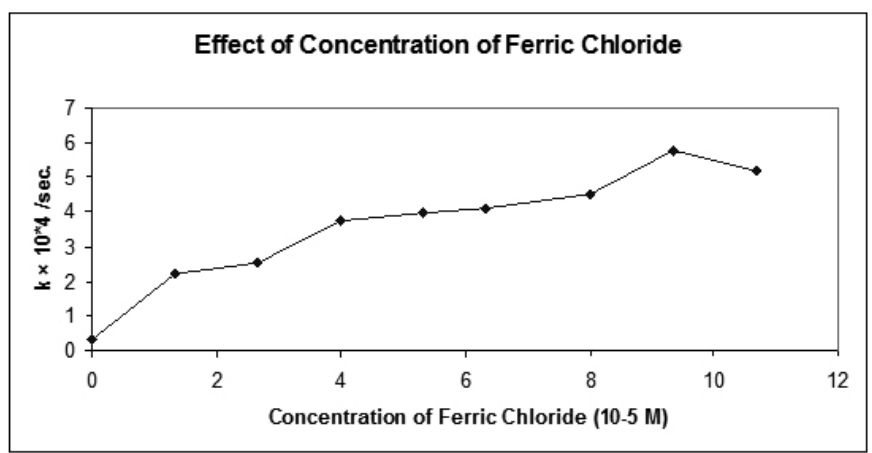

3.3 Effect of Amount of Hydrogen Peroxide

Keeping all the other parameters constant, the amount of $\mathrm{H}_{2} \mathrm{O}_{2}$ added was varied from 0.04 to $0.32 \mathrm{~cm}^{3}$ and its effect on the kinetics of photochemical reaction was observed. The result as reported in Fig. (4) indicates an increase in the rate of photo - degradation of dye with increase in the amount of $\mathrm{H}_{2} \mathrm{O}_{2}$ up to $0.16 \mathrm{~cm}^{3}$, beyond which a decrease in degradation of dye is observed. This behavior can be explained on the basis of more production of hydroxyl radicals due to increase amount of hydrogen peroxide which increase the rate of reaction. The higher concentration of hydrogen peroxide will lead to the production of perhydroxyl radicals $\left(\mathrm{HO}_{2}\right)^{\prime}$ as a result of reaction between $\mathrm{H}_{2} \mathrm{O}_{2}$ and $\mathrm{OH}$ radicals (step 7) and these radicals are having lower oxidation potential than hydroxyl radicals thus, rate of reaction is found to be decreased.

FIG - 4 : Effect of Amount of $\mathrm{H}_{2} \mathrm{O}_{2}$ on the Photo-Fenton Degradation of Dye.

\begin{tabular}{|c|c|}
\hline Methylene blue $=\left[2.33 \times 10^{-5} \mathrm{M}\right]$ & $\mathrm{pH}=3.00$ \\
\hline Resorcinol $=\left[9.33 \times 10^{-5} \mathrm{M}\right]$ & $\mathrm{FeCl}_{3}=\left[9.33 \times 10^{-5} \mathrm{M}\right]$ \\
\hline & Light Intensity $=8000$ lux \\
\hline
\end{tabular}

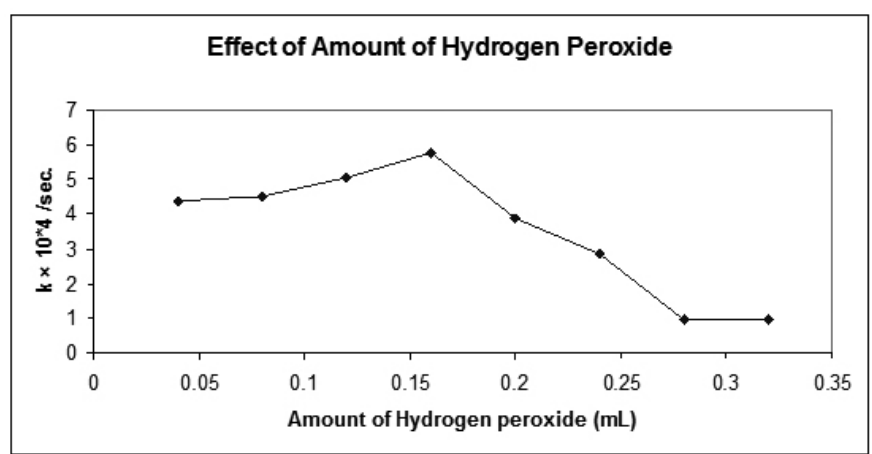

\subsection{Effect of Additive Concentration}

The concentration of additive (Resorcinol) has been varied from $1.33 \times 10^{-5}$ $\mathrm{M}$ to $10.67 \times 10^{-5} \mathrm{M}$ and its effect on the rate of photochemical degradation of dye was investigated. The results are reported in Fig. (5) which shows that rate of reaction increases with increase in concentration of additive up to 9.33 $\times 10^{-5} \mathrm{M}$ after that decrease in rate of reaction was reported. Initially resorcinol acts as a catalyst and generates ferrous ions [reactions (1)-(3)] which in turn generate hydroxyl radicals rapidly. Thus rate of degradation increases. At higher concentration additive itself oxidized by hydroxyl radicals thus decrease in rate of reaction was observed. 
<smiles>Oc1cccc(O)c1</smiles><smiles>Oc1ccc(O)c(O)c1</smiles><smiles>O=C1C=CC(=O)C(O)=CC1=O</smiles>

\subsection{Effect of Dye Concentration}

At different concentrations of dye (Methylene blue) ranging from $1.00 \mathrm{x}$ $10^{-5} \mathrm{M}$ to $4.00 \times 10^{-5} \mathrm{M}$, the effect of the dye concentration on the degradation of Methylene blue was observed by maintaining all other parameters constant. The result as reported in Fig. (6) indicates an initial increase in rate of photobleaching of dye due to availability of more dye molecules for degradation. A further increase in the dye concentration results in retardation of reaction. This can be attributed to the increased number of collisions between dye molecules themselves than the probability of collisions between dye and ${ }^{\circ} \mathrm{OH}$ radicals. In addition, at higher concentrations the dye molecules themselves may act as quenchers for the photons of the incident light, and hence prevent sufficient light intensity to reach the bulk of the solution. Hence at higher dye concentrations, a decrease in the rate of photo degradation of dye is observed.

FIG - 5 : Effect of Additive Concentration on the Photo-Fenton Degradation of Dye.

\begin{tabular}{|c|c|}
\hline Methylene blue $=\left[2.33 \times 10^{-5} \mathrm{M}\right]$ & $\mathrm{pH}=3.00$ \\
\hline Amount of $\mathrm{H}_{2} \mathrm{O}_{2}=0.16 \mathrm{~cm}^{3}$ & $\mathrm{FeCl}_{3}=\left[9.33 \times 10^{-5} \mathrm{M}\right]$ \\
\hline Light Intensity $=6000 \mathrm{lux}$ & \\
\hline
\end{tabular}

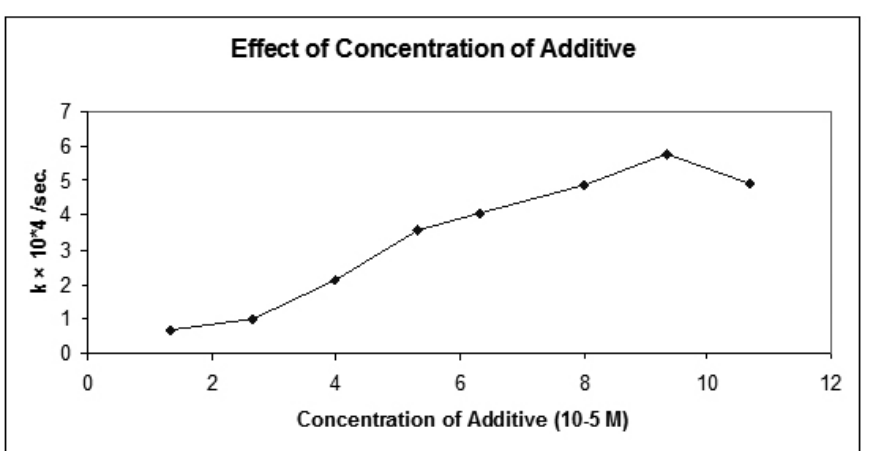

FIG. 6 : Effect of Concentration of Dye Methylene Blue on the PhotoFenton Degradation of Dye.

\begin{tabular}{|c|c|}
\hline $\mathrm{pH}=3.00$ & $\mathrm{FeCl}_{3}=\left[9.33 \times 10^{-5} \mathrm{M}\right]$ \\
\hline Amount of $\mathrm{H}_{2} \mathrm{O}_{2}=0.16 \mathrm{~cm}^{3}$ & Light Intensity $=6000 \mathrm{Lux}$ \\
\hline Resorcinol $=\left[9.33 \times 10^{-5} \mathrm{M}\right]$ & \\
\hline
\end{tabular}

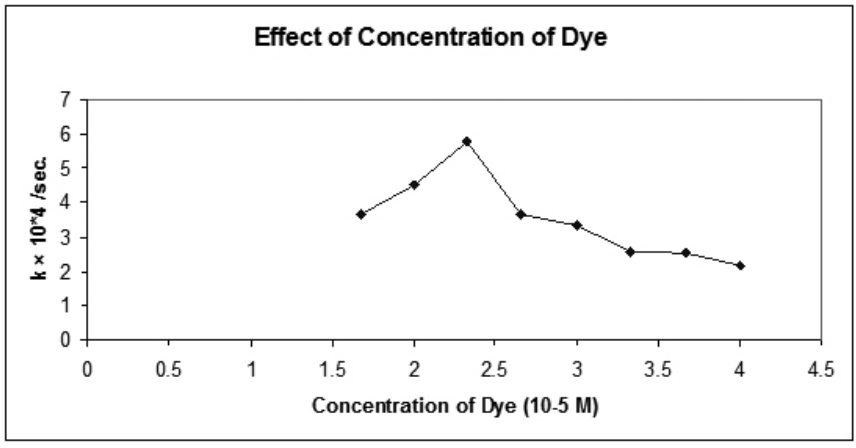

3.6 Effect of Light Intensity

The effect of variation of light intensity ranging from 2000 lux to 9000 lux on the rate of photo-Fenton degradation of Methylene blue was investigated, keeping all other parameters at their optimum value. The results shown in Fig. (7) reveals that the rate of degradation of dye shows a linear relationship with intensity of light upto 6000 lux. After that further increase in light intensity results into decrease in rate of reaction. When the intensity of light is increased, the number of photons striking on the solution increases which results in generation of more hydroxyl radicals which are responsible for the photochemical degradation of dye. At higher light intensity, probably due to some thermal reactions, the decreased rate of degradation was observed.

FIG - 7 : Effect of Light Intensity on the Photo-Fenton Degradation of Dye.

\begin{tabular}{|c|c|}
\hline Methylene blue $=\left[2.33 \times 10^{-5} \mathrm{M}\right]$ & $\mathrm{pH}=3.00$ \\
\hline Amount of $\mathrm{H}_{2} \mathrm{O}_{2}=0.16 \mathrm{~cm}^{3}$ & $\mathrm{FeCl}_{3}=\left[9.33 \times 10^{-5} \mathrm{M}\right]$ \\
\hline Resorcinol $=\left[9.33 \times 10^{-5} \mathrm{M}\right]$ & \\
\hline
\end{tabular}

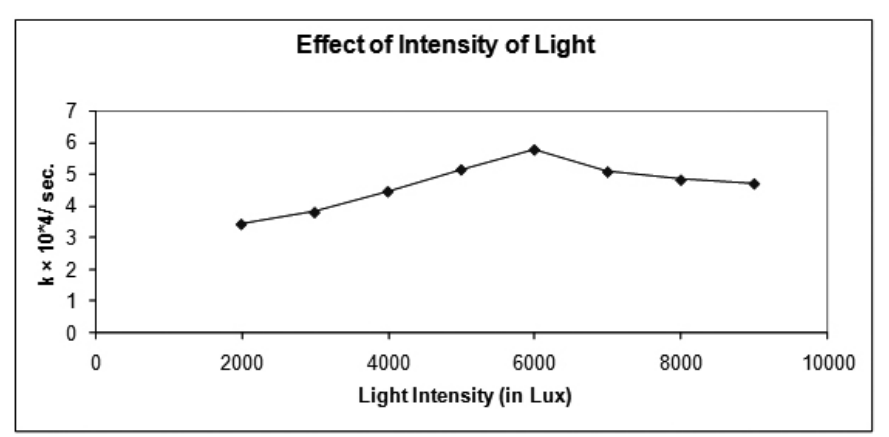

\section{MECHANISM}

On the basis of this multidimensional study and extensive literature survey ${ }^{47-49}$, a following tentative mechanism can be given for photo- Fenton degradation of Methylene blue in presence of organic additive.

$\mathrm{Fe}^{3+}+\mathrm{H}_{2} \mathrm{O}+\mathrm{hv} \rightarrow \mathrm{Fe}^{2+}+\cdot \mathrm{OH}+\mathrm{H}^{+}$

$\mathrm{Fe}^{3+}+\mathrm{H}_{2}^{2} \mathrm{O}_{2}+\mathrm{h} v \rightarrow \mathrm{Fe}^{2+}+\cdot \mathrm{O}_{2} \mathrm{H}+\mathrm{H}^{+}$

$\mathrm{Fe}^{2+}+\mathrm{H}_{2}^{2} \mathrm{O}_{2} \rightarrow \mathrm{Fe}^{3+}+{ }^{\circ} \mathrm{OH}+\mathrm{OH}^{-}$

$\cdot \mathrm{OH}+\mathrm{H}_{2} \mathrm{O}_{2} \rightarrow \mathrm{O}_{2} \mathrm{H}+\mathrm{H}_{2} \mathrm{O}$

$\mathrm{Fe}^{2+}+\cdot \mathrm{OH}^{2} \rightarrow \mathrm{Fe}^{3+}+\mathrm{OH}^{-}$

$\mathrm{Fe}^{3+}+\cdot \mathrm{O}_{2} \mathrm{H} \rightarrow \mathrm{Fe}^{2+}+\mathrm{O}_{2}+\mathrm{H}^{+}$

$\cdot \mathrm{OH}+{ }^{\circ} \mathrm{OH} \rightarrow \mathrm{H}_{2} \mathrm{O}_{2}$

Dye (Methylene blue) $+\cdot \mathrm{OH} \rightarrow$ Colourless Products

On exposure to light, the ferric ions present in the solution generate protons, $\mathrm{OH}$ radicals and ferrous ions (step 4). Ferrous ions are also generated by the reactions of ferric ions with hydrogen peroxide as well as with resorcinol in presence of light (steps 5 and 1). These ferrous ions react with $\mathrm{H}_{2} \mathrm{O}_{2}$ and generate hydroxyl ions and hydroxyl radicals and are oxidized back to ferric ions (step 6). The hydroxyl radicals, thus generated are probably the most active species in the degradation of dye.

Aromatic additive like resorcinol plays an important role in catalyzing the Fenton and photo-Fenton reactions. Resorcinol accelerates the Fenton reaction by increasing the regeneration of ferrous ion (steps (1) and (2)), which might be the slowest step in the mechanism of the simple Fenton reaction. Further, this 
type compounds are continuously regenerated from quinone or semi-quinone by reaction with ${ }^{\circ} \mathrm{O}_{2} \mathrm{H}$ radicals and disproportionation reaction of semiquinone [(12)- (14). This regeneration of hydroquinone continuously promotes the rate of the reaction.

$\cdot \mathrm{O}_{2} \mathrm{H}+$ Quinone derivative $\rightarrow$ Semiquinone $+\mathrm{O}_{2}$

$\cdot \mathrm{O}_{2} \mathrm{H}+$ Semiquinone $\rightarrow$ Hydroquinone derivative $+\mathrm{O}_{2}$ (14)

Semiquinone $\rightarrow$ Hydroquinone derivative + Quinone derivative

The role of ${ }^{\circ} \mathrm{OH}$ radicals as active oxidizing species was confirmed by using isopropanol which is a hydroxyl radical scavenger. The rate of photochemical degradation was found to be drastically reduced in presence of isopropanol.

\section{CONCLUSION}

Photo-Fenton process has been proven as one of the most promising techniques for the degradation of organic pollutants. It provides method for decomposition of dye which is benign to the nature and is economically viable too. The efficacy of this reaction can be further increased by the addition of an aromatic additive like resorcinol. In the present case, a negligible decolorization of dye was observed in the absence of additive by photo-Fenton process. Moreover, it was also observed that in absence of light and additive the rate of Fenton reaction is extremely slow. The comparative study shown in Table 1 reveals that the rate of degradation in different conditions shows the following order -

TABLE - 1 : A Comparative Study of Rate of Reaction (k) of Different Systems.

\begin{tabular}{|c|c|c|c|c|}
\hline \multirow[t]{2}{*}{ Time (mins) } & \multicolumn{2}{|c|}{ With Additive } & \multicolumn{2}{|c|}{ Without Additive } \\
\hline & In presence of Light & In Dark & In presence of Light & In Dark \\
\hline 0 & 2.141 & 2.142 & 2.159 & 2.162 \\
\hline 5 & 2.147 & - & 2.163 & - \\
\hline 10 & 2.137 & 2.138 & 2.160 & 2.160 \\
\hline 15 & 2.115 & - & 2.153 & - \\
\hline 20 & 2.056 & 2.128 & 2.145 & 2.156 \\
\hline 30 & 1.907 & 2.121 & 2.145 & 2.155 \\
\hline 40 & 1.837 & - & 2.144 & - \\
\hline 45 & 1.776 & 2.121 & 2.137 & 2.154 \\
\hline 50 & 1.716 & - & 2.139 & - \\
\hline 60 & 1.572 & 2.093 & 2.132 & 2.153 \\
\hline 65 & 1.513 & 2.070 & 2.119 & 2.151 \\
\hline 70 & 1.491 & - & 2.112 & - \\
\hline 75 & 1.459 & 2.042 & 2.110 & 2.150 \\
\hline 80 & 1.452 & - & 2.105 & - \\
\hline 85 & 1.420 & 1.997 & 2.098 & 2.146 \\
\hline 90 & 1.369 & - & 2.079 & - \\
\hline 95 & 1.338 & 1.923 & 2.079 & 2.143 \\
\hline 100 & 1.332 & - & 2.066 & - \\
\hline 105 & 1.326 & 1.872 & 2.061 & 2.145 \\
\hline 110 & 1.170 & - & 1.684 & 2.136 \\
\hline 121 & - & 1.769 & - & 2.134 \\
\hline $\mathbf{k}$ & $5.785 \times 10^{-4} \mathrm{sec}^{-1}$ & $2.42 \times 10^{-4} \mathrm{sec}^{-1}$ & $0.590 \times 10^{-4} \mathrm{sec}^{-1}$ & $0.18 \times 10^{-4} \mathrm{sec}^{-}$ \\
\hline
\end{tabular}

With Additive in Light $>$ With Additive in Dark $>$ Without Additive in Light $>$ Without Additive in Dark

The graphical representation of all the systems has also been shown in Fig. (1 A) to (1 D).

In the presence of light, the rate of regeneration of ferrous ions in the system increases through the photo-Fenton reactions (steps iv and v). The regeneration of ferrous ions in the system is also being increased by aromatic additive. Due to the regeneration of ferrous -- ferric ions and additive in the system, the entire process can be considered as cyclic and due to which a very less concentration of reagents are required for the degradation of dye. In addition to that all the chemicals used in the reactions are less hazardous to the environment thereby providing an eco-friendly or green chemical pathway for decomposition of the dye. The whole process has been depicted diagrammatically in Fig. (8).

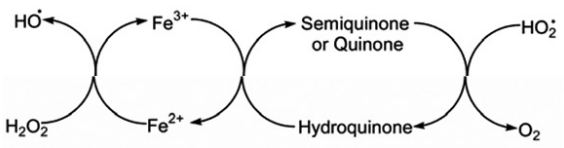

FIG. 8

\section{ACKNOWLEDGEMENT}

The authors are thankful to the Head, Department of Chemistry for providing all the necessary facilities and grant to conduct this research work. And also thankful to Vinu Varghese, Prasenjit Srivastava and Ankita Isor for their sincere \& persistent efforts and dedicated co-operation. 


\section{REFERENCES}

1.- P. Pitter and J. Chudoba, Biodegradability of Organic Substances, CRC Press, Boca Raton, 1990.

2.- M. M. Halmann, Photodegradation of Water Pollutants, CRC Press, Boca Raton, 1996.

3.- L. Lave and H. J. Gruenspecht, J. Air Waste Mange Assoc., 1991, 41, 680.

4.- K. Hunger, Industrial Dyes: Chemistry Properties And Applications, Wiley-VCH, Heidelberg, 2003.

5.- T. Robinson, G. McMullan, R. Marchant and P. Nigam, Bioresour. Technol., 2001, 77, 247.

6.- J. Shore, Colorants and Auxiliaries Vol 1. Colorants, Society of Dyers and Colourists: Bradford, 1990.

7.- T. Robinson, B. Chandran and P. Nigam, Water Res., 2002, 36, 2824.

8.- Nogueira R.F.P., Silva M.R.A and Trovo A.G. , Solar Energy, 2005, 79, 384.

9.- $\quad$ T. Francesc, G.M. Julia, A.G. Jose, D. Xavier, P. Jose Solar Energy, 77 (2004), pp. 573-581.

10.- Gernjak W., Krutzler, T., Glaser A, Malato S., Caceras J. , Bauer R., Fernandez-Alba, A.R., Chemosphere 2003 , 50, 71-78.

11.- Walling, C. Acc. Chem. Res. 1998, 31, 155-157.

12.- Ensing, B.; Buda, F.; Blochl, P.;Baerends, J. E., Angew. Chem., Int. Ed. 2001, 40, 2893-2895.

13.- Kunal, A.; Hata,S.; Sorato Ito; Sasaki, K., J. Am. Chem. Soc. 1986, 108, 6012-6016.

14.- Zepp, R.G.; Faust, B.; Hoigen, J., Environ. Sci. Technol.1992,26, 313319.

15.- Goldstein, S.; Meyerstein, D. , Acc.Chem.Res.1999, 32, 547-550.

16.- Fenton, H. J. H. , J. Chem. Soc.1894, 6, 899-910.

17.- Brinkmann, T.; Horsch, P.; Sartorius, D.; Frimmel, F. H. , Environ. Sci. Technol. 2003, 37, 4190- 4198.

18.- J.J. Pingatello Environ. Sci. Technol., 26 (1992), pp. 944-951

19.- Muruganandham M. and Swaminathan M., Sep. Purif. Technol. 2006, 48, 297.

20.- Walling, C.; Goosen, A., J. Am. Chem. Soc. 1973, 95, 2987-2991.

21.- L. Gomathi Devi, K.S Anantha Raju, S. Girish Kumar, K. Eraiah Rajashekhar, Journal of the Taiwan Institute of Chemical Engineers. 2011, 42-2, 341-349.

22.- Tran T ThanhThuya, b, Hui Fenga, Quingyun Caia, Chemical Engineering Journal. 2013, 223, 379-387.

23.- B. Trybaa, M. Piszcza, B. Grzmilla,A. Pattek-Janczybk, A.W. Morawskia, Journal of Hazardous Materials. 2009, 162-1, 111- 119.

24.- Hamilton, G. A.;Hanifin, J.W.; Friedman, J. P., J. Am.Chem. Soc. 1966, $88,5269-5272$

25.- M.Lu, J.Chen and C.Chang, Chemosphere, 1997, 35, 2285.

26.- V.Nadtoch enko and J.Kiwi, Environ. Sci. Technol., 1998, 32, 3282.

27.- K.A.Hislop and J.R.Bolton, Environ. Sci. Technol., 1999, 33, 3119.

28.- M.E.Balmer and B.Sulzberger, Environ. Sci. Technol., 1999, 33, 2418.

29.- G. A.Hamilton, J.W.Hanifin and J.P.Friedma n, J. Am. Chem. Soc., 1966, 88,5269

30.- R.Z.Chen and J.J. Pignatello, Environ. Sci. Technol., 1997, 31,2399.

31.- F.Chen, W.Ma, J.He and J. Zhao, Environ. Sci. Technol., submitted.

32.- Chen, F.; He, J.; Zhao, J.; Yu, J.C. , New J. Chem. 2002, 26,336-341.

33.- Ramakrishnan, .; Singh, K.; Patil, K.; Ghosh, J. Phys.Chem. B 2004, 108, 4775-4783.

34.- Mae, K.; Shindo,H.; Miura, K. , Energy Fuels 2001, 15, 611-617.

35.- Chen, R.; Pignatello, J. J., Environ. Sci. Technol. 1997, 31, 2399-2406.

36.- Chen, F.; Ma, W.; He, J; Zhao, J., J. Phys. Chem. A 2002, 106 9485-9490.

37.- Chen, F.; He, J.; Zhao, J.; Yu, J. C., New J. Chem. 2002, 26, 336-341.

38.- Wu, K.; Zhao, T.; Zhao, J.; Hidaka, H. , Chem. Lett. 1998, 857-858.

39.- Wu, K.; Xie, Y.; Zhao, J.; Hidaka, H., J. Mol. Catal., A 1999, 144, 77-84.

40.- Sun, Y.; Pignatello, J. J., Sci. Technol.1993, 27, 304-310.

41.- Zuo, Y.; Hoigne, J. , Environ. Sci. Technol.1992, 26, 1014.

42.- Herrera, F.; Kiwi, J.; Lopez, A.; Nadtocheko, V. , Sci. Technol. 1999, 33, 3145-3151.

43.- Santhanalakshmi J and Komalavalli R., Res. J. Chem. Sci. 2012, 2(4), 64-67.

44.- Munesh Swati and Meena R. C., Res. J. Chem. Sci. 2012, 2(9), 56-62.

45.- Fei Ji, Chaolin, Jiahuan Zhang, Lei Deng. , Journal of Hazardous Materials. 2011, 186- (2,3),1979-1984.

46.- Yuanyuan Gao, Huihui Gan, Gaoke, Yadan Guo, Chemical Engineering Journal. 2013, 217, 221-230.
47.- Neamtua M, Yediler A, Siminiceanu I and Kettrup A 2003 J. Photochem. and Photobiol. A: Chemistry 16187

48.- Nilesh P. Tantak N P and Chaudhari S. 2006 J. Hazard. Mater. B 136698

49.- Chen F, He J, Zhao J and Yu J C 2002 New J. Chem. 26336 